\title{
Use of Clove extract against the larvae of Aedes (Culicidae: Diptera) mosquitoes ${ }^{*}$ C.L. Baghel ${ }^{1}$, M.K. Gupta ${ }^{2}$ and A.K.JHA ${ }^{3}$
}

\author{
${ }^{1}$ Filaria Control Unit JALAUN, ORAI, INDIA \\ ${ }^{2}$ BIET, JHANSI (U.P.) INDIA \\ ${ }^{3}$ D.A.V College, KANPUR, INDIA \\ ${ }^{*}$ Corresponding Author \\ E-mail : baghelc@yahoo.co.in
}

Received : 15.08.2020; Revised : 16.09.2020; Accepted : 12.10 .2020

\begin{abstract}
Insecticides have been commonly used to vector control. The current study has been made to evaluate the effect of Syngium aromaticum (clove oil) against the larvae of Aedes for their biocidal activity. The oil can be used in domestic container due to its biodegradable and unharmful nature. The toxicity of insecticides affects the environment. Antilarval activities were studied using clove oil with methanol and ether separately in different concentrations. The bioassay has been made against the third / early fourth stage larvae of Aedes mosquito. These were exposed with control and clove oil concentrations of 20ppm, $30 \mathrm{ppm}$ and $50 \mathrm{ppm}$. The bioassay test has been made for the first time to know the efficacy of clove oil against mosquito larvae and check the mortality within 24 hrs.

Figure : 01

References : 18

Tables : 03

KEY WORDS : Aedes, Chikunguniya, Clove oil, Dengue vector, Ether, Methanol , Micro pipette, Mortality, Natural extracts.
\end{abstract}

\section{Introduction}

Mosquito borne diseases are due to the unplanned urbanization, industrialization and excessive population growth spreading from rural to urban. It also grows due to large and small water bodies, as small scale reservoir like domestic containers. It develops due to poor administration and failing of epidemic act. For developing the suitable and effective health education strategy, it is inevitable to understand the level of knowledge of the community, their attitude and practices for protection regarding mosquito borne diseases.

A number of serious human life threatening diseases were investigated; some of them were transmitted by different mosquito species causing millions of human deaths every year, disability, morbidity and burden on the large poor group of society.

These diseases are burden, social stigma and devaste human economy. The intensive and indiscriminate use of synthetic insecticides cause resistance rebounding vectorial capacity and spread other parasitic diseases. It is necessary to intervene the proliferation of mosquito borne diseases and improve the quality of public health environment. In recent years, use of many synthetic insecticides for mosquito control program has been limited due to the non-biodegradable nature.

Resistance has been developed in larvae of Aedes and Culex fatigans against phenthion due to the continuous use. Plant products may be the alternative sources of mosquito control. Instructions have been made for determining the susceptibility or resistance against mosquito larvae to insect development inhibitor ${ }^{18}$. Scientists ${ }^{7}$ studied the resistance to methoprene against the Aedes taeniorhynchus. Insecticide susceptibility status temephos agaist Aedes aegypti and Anophelese stephesi in Delhi, was studied ${ }^{17}$. Molecular analysis of Kdr- like resistance in insecticide resists strains of head lice ${ }^{14}$. Independent mutations in the Rdl locus confer dieldrin resistance to Anopheles gambiae and An. apheles arabiensi ${ }^{8}$.

Experiments have been made on the repellency of Lantana camara (Verbenaceae) flower against Aedes mosquitoes ${ }^{9}$ New mosquito larvicide was screened from

ACKNOWLEDGEMENTS : The authors wish to express sincere gratitude to Dr S. Dutta, Ex. Reader and Head, Department of Zoology, Narayan (P.G.) College Shikohabad, Firozabad (U.P.) INDIA for his precious suggestions and we also pay lot of thanks with our deepest core of heart to Dr S.B. Mishra, Additional Director, Medical Health and Family welfare, Jhansi division Jhansi, (U.P.) INDIA and Dr Alpana Bartaria , C.M.O. Jalaun at Orai for providing required laboratory facilities and also thanks to Mr Surjeet Singh and our staff members for assisting in the lab work. Finally we gratefully acknowledge our families for their unfailing emotional support during the work. 


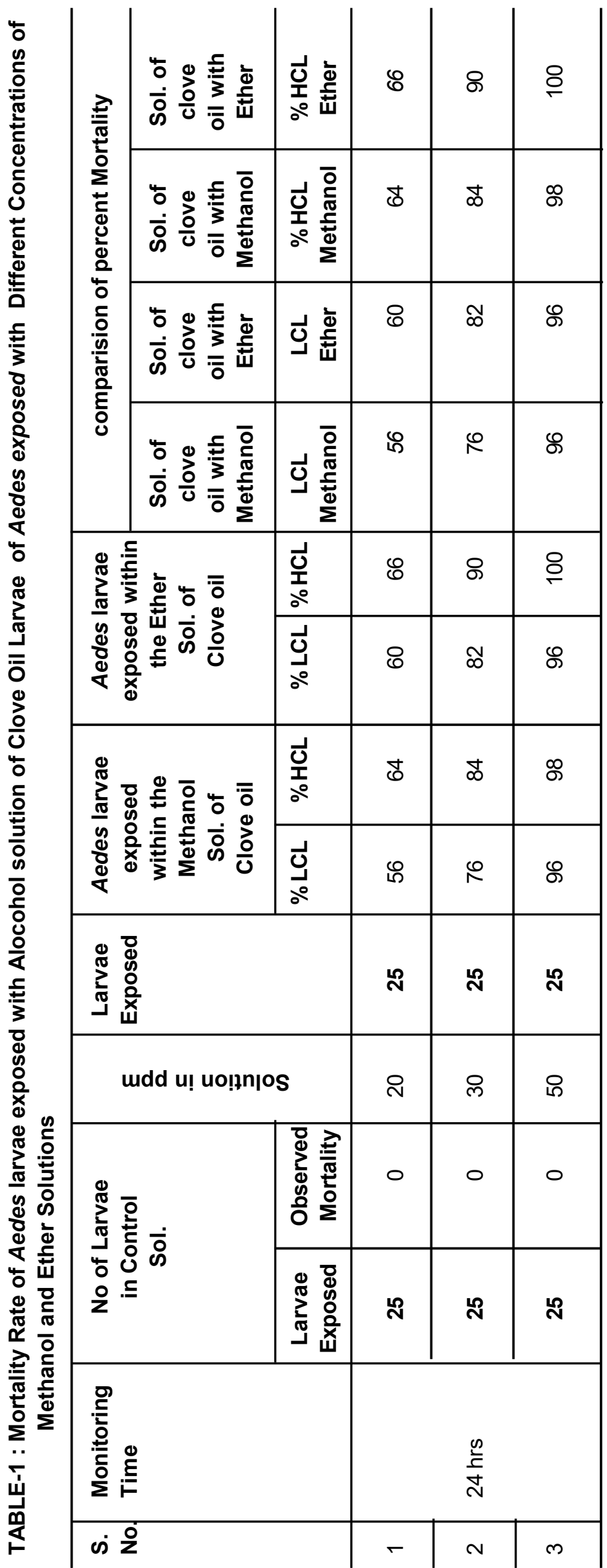

plants of semiarid zone ${ }^{10}$ Larvicidal efficacy of Ficus bengalensis and Cassia fistula ${ }^{11-13}$ plant leaf extracts against Culex quinquefasciatus, Aedes aegypti and Anopheles stephensi were also studied. Larvicidal activity of medicinal plant extracts against Anopheles stephensi and Culex tritaeniorhynchus were studied ${ }^{15}$. Emeritus scientist ${ }^{16}$ recorded the mechanisms of insecticides resistance in field population of Culex pipiens from Italy.

Earlier researchers ${ }^{2}$ recorded the larvicidal and repellent action of Dalbergia sissoo oil against mosquito while another scientist ${ }^{6}$, investigated the alternative substitute of the insecticides. Working on the vector borne disease control aspect; significant reduction in density of Dengue and Chikungunya disease vectors Aedes by phytoproduct Azadirachtin and use of turpentine oil against the larvae of Anopheles, Aedes and Culex were observed. The insecticidal properties of indigenous plant neem products have been recorded ${ }^{4,5}$.

There is a renewed interest in plant essential aromatic oils as source of new insect controlling agents because they may be biodegradable and nontoxic compounds for human, thus minimizing the accumulation of harmful residues, leading them to be more eco- friendly in comparison to synthetic compounds. This is especially true for the use of natural products based on plant essential oils (PEOs) as insecticides and repellents ${ }^{3-8,12,13}$. Further, more study is needed to investigate the histopathology of dead larvae.

\section{Materials and Methods}

COLLECTION: The larvae were collected with the help of ladle and dropper from clean stagnant and ideal breeding sites, coolers, domestic containers, cement tanks, discarded plastic tubs and buckets from various locality of Orai city: Rajendra Nagar, Pathak Pura, Pathak ka Bagicha, Sushil Nagar, Patel Nagar and Baldau Choak etc. Essential oil. The clove oil purchased from the open market. The samples were stored at room temperature. Formulation of clove oil solution: The solutions were made with methanol and ether of different concentrations. These were kept in the refrigerator as stock to maintain its original potency. Micropipette was used to measure the accuracy of the solution.

TEST ORGANISMS; Larvae of Aedes were brought to the Entomological laboratory of Filaria 
TABLE -2 : Mortality rate of Aedes larvae exposed with Alcohol and Ether solution of Clove Oil

\begin{tabular}{l|c|c|c|c|c}
\hline S.No. & $\begin{array}{c}\text { Concen- } \\
\text { tration }\end{array}$ & $\begin{array}{c}\text { Sol. of } \\
\text { clove oil with } \\
\text { Methanol }\end{array}$ & $\begin{array}{c}\text { Sol. of } \\
\text { clove oil } \\
\text { with Ether }\end{array}$ & $\begin{array}{c}\text { Sol. of } \\
\text { clove oil with } \\
\text { Methanol }\end{array}$ & $\begin{array}{c}\text { Sol. of } \\
\text { clove oil } \\
\text { with Ether }\end{array}$ \\
\cline { 2 - 6 } & $\begin{array}{c}\text { \% LCL } \\
\text { Methanol }\end{array}$ & $\begin{array}{c}\text { \% HCL } \\
\text { Methanol }\end{array}$ & $\begin{array}{c}\text { \% LCL } \\
\text { Ether }\end{array}$ & $\begin{array}{c}\% \text { LCL } \\
\text { Ether }\end{array}$ \\
\hline 1 & 20 & 56 & 60 & 64 & 66 \\
\hline 3 & 30 & 76 & 82 & 84 & 90 \\
\hline
\end{tabular}

Control Unit Jalaun. These were held at room temperature and relative humidity $21^{\circ \mathrm{c}}$ to $36^{\circ \mathrm{c}}$ and nearly $75 \%-85 \%$.

BIOASSAY TEST. During the study; early $\mathrm{iii}^{\text {rd }} / \mathrm{iv}^{\text {th }}$ stage larvae were chosen. The crushed dog biscuits dissolved in the water as artificial food and larvae were poured. Four Jars were taken for study and each Jar filled with one liter of water. Twenty five larvae of Aedes were poured in control and experimental solution with concentration of $20 \mathrm{ppm}$, $30 \mathrm{ppm}$ and 50ppm. Keeping in solution upto $24 \mathrm{hrs}$ and then checked.

\section{STATISTICAL ANALYSIS}

Lowest and highest confidence limit has determined for the calculation. The mortality rate has been observed, calculated and corrected ${ }^{1}$.

Test mortality_\% control mortality

$\%$ Mortality $=\frac{}{100-\% \text { control mortality }} \times 100$

\section{Result and Discussion}

Study has been made in different concentrations of methanol and ether solutions of clove oil treated for larvae of Aedes mosquito. Twenty five larvae of Aedes were exposed with the methanol solution of Syzygium aromaticum showed 56-64\% mortality with 20ppm, 76$84 \%$ mortality with 30ppm while; $96-98 \%$ mortality with $50 \mathrm{ppm}$. In ether and clove oil solution, twenty five larvae were exposed which showed $60-66 \%$ mortality with 20ppm, 82- $90 \%$ mortality with 30ppm while; 96-100\% mortality have been observed with 50ppm (Table-1).

Comparison has been made with the methanol and ether solution of clove oil. Larval mortality was better with ether solution than that of methanol solution of Syzygium aromaticum . Symptoms of toxicity on larvae were seen by coiling with slow movement of the individuals along with the tremor and convulsion as an instant reaction to exposure to the different concentrated solutions. It was monitored after 24 hours of exposure in different concentrations; all the larvae were found dead and sank at the bottom of the jar (Fig. 1).

The clove oil mixed with methanol and ether shows lower larvicidal activity of Aedes larvae in comparison to ether (Table-2).

Our study is better than the previously studied ${ }^{4-6}$ with the methanol solution of turpentine oils (Table-3). The pioneer scientists s,9,11-15 showed the larvicidal efficacy with the methanol solution of Delbergia

TABLE -3 : Comparison of Earlier Study to current Study

\begin{tabular}{|c|c|c|c|c|c|c|c|c|}
\hline \multirow[t]{2}{*}{ S.No } & \multirow{2}{*}{$\begin{array}{c}\text { Name of } \\
\text { Mosquito } \\
\text { genera }\end{array}$} & \multirow[t]{2}{*}{ Solution } & \multicolumn{2}{|c|}{ Azadirachatin oil } & \multicolumn{2}{|c|}{ Turpentilane oil } & \multicolumn{2}{|c|}{ Clove oil } \\
\hline & & & LCL/50 & HCL100 & LCL/50 & HCL/100 & LCL20 & HCL/50 \\
\hline 1 & \multirow[t]{2}{*}{ Aedes } & Methanol & 52 & 92 & 56 & 92 & 56 & 96 \\
\hline 2. & & Ether & 56 & 98 & 60 & 100 & 60 & 100 \\
\hline
\end{tabular}




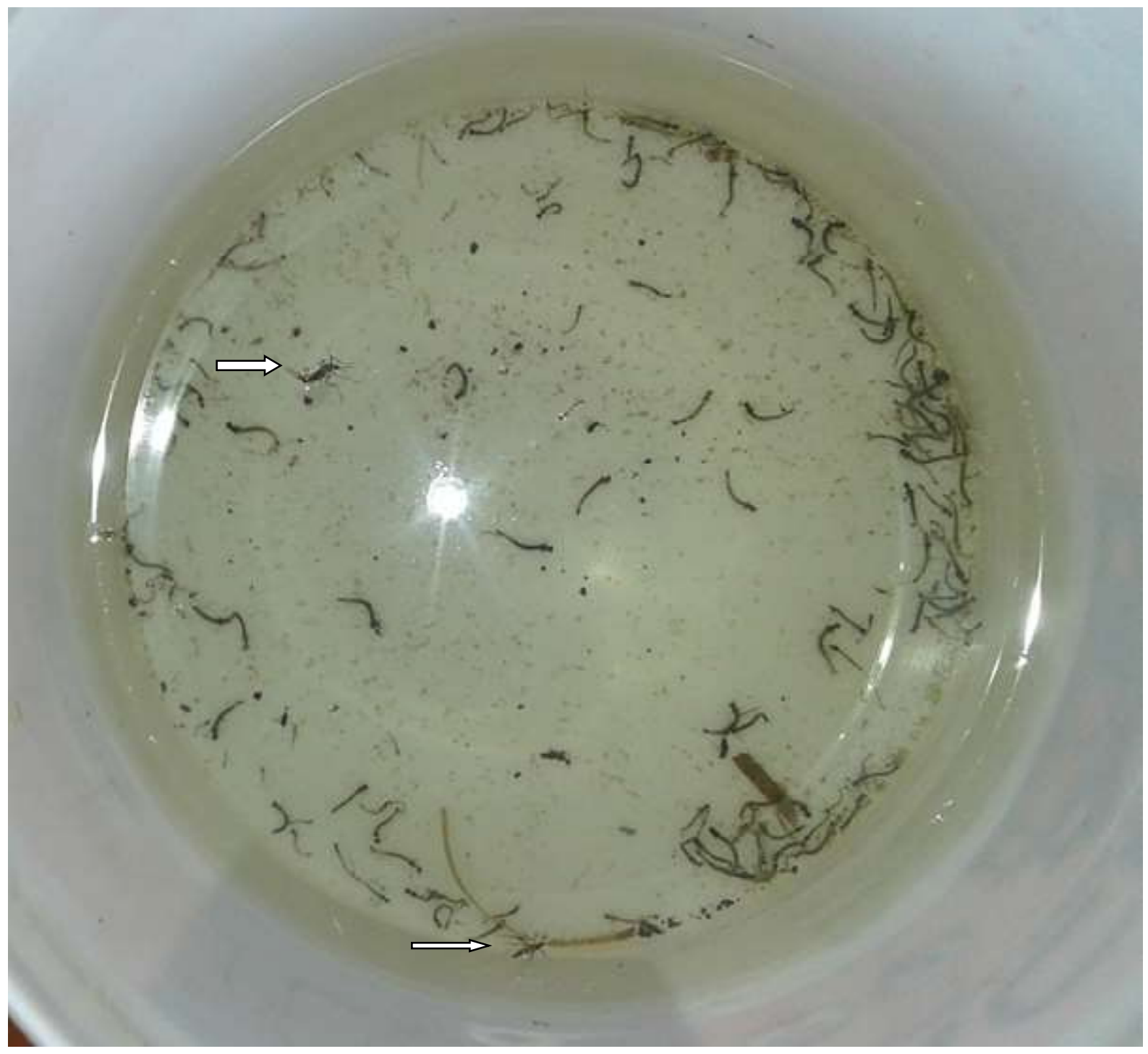

Fig. 1 : Showing the sank larvae and emerging adult from pupa of Aedes

sisso, Ficus benfalensis and Cassia fistula against Culex quiquefasciatus, Culex tritaeniorhynchus, Anophelese subpictus which are poor than that of our study. Current study showed the $100 \%$ mortality within 50 ppm whlle in previous study showed the $100 \%$ mortality within 100 ppm (Table-3).

The result of our study showed very good mortalities in 50ppm clove oil solution of ether and it showed better results than that of earlier workers studied ${ }^{4-6}$. Longevity of different larval stages were observed in the developing time of different larval stages and also paralysed the body of the larvae of Aedes albopictus Skuse in very low concentration as well as in high concentration it showed quick mortality.

The present study has confirmed good biocidal potential of Syzygium aromaticum oil against the larvae of Aedes. In our study there is environmental feasibility and plentiful availability of the clove oil at reasonable market price. However; more research work is needed for optimization of the formula for field condition and large scale applications to upgrade the product. With this we observed the emerging process of adult from pupa at the time of experiment and also found that there is no impact on the pupae stage (Fig. 1).

\section{References}

1. Abbott WS. A method of computing the effectiveness of insecticides. J.Econ.Entomol. 1925; 18: 256-267

2. Ansari MA, Razadan RK, Tondan M, Vasudevan P. Larvicidal and repellent action of Dalbergia sissoo Roxb. (F. Laguminasae) oil against mosquito. Biosource Technology. 2000; 83 (3):207-211. 
3. Bagavan A, Rahuman A, Kamaraj C, Geetha K. Larvicidal activity of Saponin from Achyranthes aspera against Aedes aegypti and Culex quinquefasciatus (Diptera: Culicidae). Parasitol. Res. 2008; 103 (1): 223-229.

4. Baghel CL, Srivastav AK. Significant reduction in density of Dengue and Chikungunya disease vectors Aedes by phytoproduct Azadirachtin. Flora and Fauna. 2006; 12 (2) : 295-297.

5. Baghel CL, Srivastav AK, Gupta MK, Amit Kumar. Larvicidal efficacy of Azadirichtin and Turpentine oil against the larvae Aedes mosquito. Flora and Fauna. 2016; 22 (2) : 225-231.

6. Baghel CL, Gupta MK. Use of Turpentine oil against the larvae of Anopheles, Aedes and Culex (Culicidae: Diptera) Flora and Fauna. 2018; 24 (1) : 202-208.

7. Dam D, Witchman GJ, Horny JA. Mosquito (Aedes taeniorhynchus) resistance to methoprene in an isolated habitat. J. Am mosq. control assoc. Entomol. 1998; 14 : 200-203.

8. Du W, Awolola TS, Howell P, Koekemoer LL, Brooke BD, Benedict MQ, Coetzee M, Zheng L. Independent mutations in the Rdl locus confer dieldrin resistance to Anopheles gambiae and An. arabiensis. Insect. Mol. Biol. 2005; 14 : 179-183.

9. Dua VK, Gupta NC, Pandey AC, Sharma VP. Repellency of Lantana camara (Verbenaceae) flower against Aedes Mosquitoes. J. of American mosquito control Association. 1996; 121 (3): 406-408

10. Dwivedi SC, Garg S, Amita Kumari. Screening of new mosquito larvicides from plants of semiarid zone. Ind.Biologist. 2000; 32: 25-28.

11. Govindarajan M. Larvicidal efficacy of Ficus bengalensis L. plant leaf extracts against Culex quinquefasciatus Say, Aedes aegypti L. and Anopheles stephensi L. (Diptera: Culicidae). Eur. Rev. Med. Pharmacol. Sci. 2010; 14 (2) : 107-111.

12. Govindarajan M. Larvicidal efficacy of $C$. fistula Linn. leaf extracts against Culex tritaeniorhynchus Giles and Anopheles subpictus Grassi (Dipters Culicidae) Asian Pacific Journal of tropical diseases. 2011; 295-298.

13. Govindarajan M. Larvicidal activity of $C$. fistula Linn. Flower extract against Culex tritaeniorhynchus Giles, Aedes albopictus Skuse, and Anopheles subpictus. Grassi (Diptera: Culicidae). International Journal of pure and applied Zoology. 2013; 1 (2): 111-121.

14. Lee SH, MS, Williams KS, Yoon M Takano, Lee JD, Edmana L Devonshire, JM Clark. Molecular analysis of Kdrlike resistance in insecticide resist strains of head lice.Pestic. Biochem. Physil. 2000; $66: 130-143$.

15. Kamaraj C, Bagavan A, Elango G, Zahir AA, Rajkumar G, Mariamuthu. Larvicidal activity of medicinal plant extracts against Anopheles stephensi and Culex tritaeniorhynchus. Indian J. Med. Res. 2010; 134 :101- 106.

16. Marinucci M, Raymond M. Mechanisms of insecticides resistance in field population of Culex pipiens from Italy. J. Am Mosq. Control Ssoc. 1993; 9:164-168.

17. Singh RK, Kumar G, Mittal PK, Dhiman RC. Insecticide susceptibility status of temephos against Aedes aegypti and Anophelese stephesi in Delhi,India.vector in India- Review. Journal of Mosquito Research. 2014.

18. WHO. Instructions for determining the susceptibility or resistance mosquito larvae to insect development inhibitor WHO/VBD/81. 1981; 812 : PP 1-6. 